\title{
MIKROENKAPSULAT MINYAK BELUT (Monopterus albus) BEROMEGA-3 SEBAGAI FORTIFIKAN KEJU COTTAGE
}

\author{
Florentina Maria Titin Supriyanti*, Devita Putri Herwiandani, \& Ali Kusrijadi \\ Prodi Kimia, Departemen Pendidikan Kimia , Universitas Pendidikan Indonesia \\ *Alamat korespondensi: florentinasupriyanti@yahoo.co.id
}

\begin{abstract}
Abstrak: Minyak belut merupakan salah satu sumber asam lemak tak jenuh ganda atau polyunsaturated fatty acid (PUFA). Penelitian ini bertujuan untuk fortifikasi keju cottage menggunakan mikroenkapsulat minyak belut. Metode yang digunakan pada penelitian ini meliputi mikroenkapsulasi freeze drying dan karakterisasi produk mikroenkapsulat yang meliputi penentuan formulasi terbaik, rendemen, ukuran mikrokenkapsulat, efisiensi mikroenkapsulat, dan kadar air. Keju cottage hasil fortifikasi dengan mikroenkapsulat minyak belut dianalisis kandungan asam lemaknya dengan GC-MS, dan tingkat kesukaan dengan uji hedonik. Berdasarkan hasil penelitian didapat kandungan omega-3 pada minyak belut sebesar 11,26\%. Formulasi terbaik bahan penyalut pada produksi mikroenkapsulat minyak belut adalah, maltodekstrin : gum arab 5:1 ; rendemen 74\% b/b; ukuran mikroenkapsulat 10-50 $\mu$ m; efisiensi mikroenkapsulat $64 \%$ dan kadar air mikroenkapsulat 1,03\%. Berdasarkan uji hedonik yang dilakukan, didapat bahwa keju cottage terfortifikasi $10 \%$ memiliki tingkat kesukaan warna dan tekstur yang tertinggi. Hasil GC-MS menunjukkan bahwa kandungan asam lemak omega-3 pada keju cottage terfortifikasi minyak belut yang terukur sebesar $6,42 \%$.
\end{abstract}

Kata kunci: fortifikasi, keju cottage, mikroenkapsulasi, minyak belut

\begin{abstract}
Eel oil is one source of polyunsaturated fatty acids ( PUFA). This study aims to fortify cottage cheese using eel oil microencapsulate. The method used in the study were freeze drying microencapsulation and characterization of microencapsulate which includes determinition of the best formulation, yield, size of microencapsulate, microencapsulate efficiency, and water content. Cottage cheese fortification with microencapsulat was analyzed by GCMS and hedonic test. Based on the research results the omega-3 content in eel oil was $11.26 \%$. The best formulation of the coating material in the production of eel oil microencapsulate using; maltodextrin : gum arabic was $5: 1$; with yield of $74 \% \mathrm{w} / \mathrm{w}$; aparticle size of 10 $50 \mu \mathrm{m}$; an efficiency of $64 \%$ and a microencapsulate water content was $1.03 \%$. Based on the hedonic test, it was found that $10 \%$ fortified cottage cheese has the highest color and texture preference level. GCMS results showed that the content of omega - 3 fatty acids in the fortified cottage cheese was $6.42 \%$.
\end{abstract}

Keywords : fortification, cottage cheese, microencapsulation, eel oil.

\section{PENDAHULUAN}

Minyak belut merupakan salah satu sumber asam lemak tak jenuh ganda atau polyunsaturated fatty acid (PUFA) selain minyak salmon. Menurut Razak (2000), kandungan EPA dan DHA pada belut sawah cukup tinggi yaitu $7,16 \%$. Banyak publikasi ilmiah menyarankan, bahwa konsumsi rutin sejumlah besar asam lemak tak jenuh ganda atau polyunsaturated fatty acid (PUFA) khususnya omega-3, yang diantaranya Eicosapentaenoic acid (EPA) dan Docosapentaenoic acid (DHA) baik untuk kesehatan. Salah satu yang mendasarinya ialah studi epidemologi tahun 1970 pada orang eskimo. Pada studi tersebut diketahui bahwa orang eskimo jarang terkena penyakit jantung koroner, karena dikaitkan dengan pendapat bahwa konsumsi makanan orang eskimo banyak mengandung asam lemak tak jenuh khususnya EPA dan DHA. Sejak tahun 1972 asam lemak omega-3 telah diakui memiliki peranan penting bagi kesehatan. Menurut Mediana (1995), EPA dapat memperbaiki sistem sirkulasi dan dapat membantu pencegahan penyempitan dan pengerasan pembuluh darah (atherosclerosis) dan penggumpalan keping darah (thrombosis). Akhir-akhir ini penelitian terhadap sistem syaraf pusat menunjukkan bahwa DHA penting bagi perkembangan manusia. Pada masa bayi, DHA memiliki konsentrasi yang sangat tinggi dalam otak dan jaringan retina.

Minyak belut potensial dijadikan bahan tambahan makanan pada bahan makanan yang memiliki sedikit kandungan asam lemak tak jenuh ganda, seperti pada keju cottage. Namun sebagian besar upaya penambahan minyak hewani pada suatu sumber bahan makanan mengalami kesulitan, karena sifat minyak hewani yang mudah teroksidasi dan menimbulkan bau dan rasa amis. Untuk itu perlu dilakukan penyalutan minyak belut tersebut menggunakan teknik mikroenkapsulasi.

Penelitian terkait mikroenkapsulasi yang pernah dilakukan oleh peneliti sebelumnya, yaitu menurut Sathivel dan Kramer (2010) bahwa mikroenkapsulasi dapat digunakan untuk mengurangi oksidasi minyak ikan. Juga telah diteliti mengenai pengembangan yoghurt strawbery yang mengandung minyak ikan salmon yang telah dilakukan mikroenkapsulasi, serta analisis sifat fisik, kimia, dan mikrobiologi produk 
(Estrada, 2011). Gupta et al. (2014) telah berhasil membuat mikrokapsul zat besi menggunakan bahan penyalut campuran gam arab, malto dekstrin, dan tepung termodifikasi dengan perbandingan 4:1:1 menggunakan metode penguapan vakum pelarut. Mikrokapsul yang dihasilkan memiliki nilai efisiensi enkapsulasi 91,58\%. Menurut De souza et al. (2013) teknik mikroenkapsulasi telah diaplikasikan melalui pembentukan membran impermeable sebagai penghalang penguraian oleh oksigen.

Namun demikian penelitian terkait mikroenkapsulasi minyak belut yang digunakan sebagai fortifikan pada keju cottage belum pernah dilakukan. Berdasarkan uraian tersebut tujuan dari penelitian ini adalah melakukan fortifikasi keju cottage dengan menggunakan mikroenkapsulat minyak belut.

\section{METODE PENELITIAN}

Alat dan Bahan

Peralatan yang digunakan pada peneli tian ini meliputi alat-alat gelas, neraca analitik, blender, saringan, botol, heater, rotary evaporator, freeze dryer, GC-MS, dan SEM. Tahapan penelitian yang dilakukan meliputi tahap ekstraksi dan pemurnian minyak belut; formulasi dan produksi mikroenkapsulat minyak belut; pembuatan keju cottage; dan fortifikasi mikroenkapsulat minyak belut pada keju cottage.

\section{Ekstraksi dan pemurnian minyak belut}

Ekstraksi dilakukan pada suhu $75{ }^{\circ} \mathrm{C}$ selama 30 menit dengan menggunakan pelarut air. Filtrat yang diperoleh kemudian dimurnikan dengan cara degumming, netralisasi, bleaching dengan menggunakan bentonit dan pemisahan (Kusdiantini, 2010). Hasil dari keseluruhan proses didapat minyak belut yang murni. Minyak belut kemudian dianalisis jenis asam lemaknya dengan menggunakan GC-MS.

\section{Formulasi dan produksi mikroenkapsulat}

Formulasi mikroenkapsulat dilakukan menggunakan metode trial and error. Sebanyak $7 \%$ minyak belut diemulsikan dengan menggunakan $60 \%$ air dan bahan penyalut (gom arabic dan maltodekstrin) dengan perbandingan $5: 1 ; 4: 2 ; 3: 3$; 2:4. Emulsi cair kemudian di keringkan dengan menggunakan freeze dryer dan dihasilkan mikroenkapsulat minyak belut. Mikroenkapsulat yang dihasilkan dikarakterisasi yang meliputi rendemen; efisiensi mikroenkapsulat; ukuran mikroenkapsulat; tingkat oksidasi bersadarkan bilangan iod ; bilangan peroksida; dan kadar air.

\section{Pembuatan keju cottage}

Pembuatan keju cottage dilakukan dengan menggunakan bahan susu skim. Susu skim dipasteurisasi pada suhu $70{ }^{\circ} \mathrm{C}$ selama 10 menit. Susu hasil pasterisasi diinokulasi dengan $10 \%$ bakteri starter (Streptococus thermophlillus dan
Lactobacillus lactis dalam medium MRSA) dalam inkubator dengan pada suhu $30{ }^{\circ} \mathrm{C}$, lalu diamati hingga ada perubahan $\mathrm{pH}$ menjadi 4,6-4,7. Setelah ada penurunan $\mathrm{pH}$, setiap $200 \mathrm{~mL}$ susu ditambahkan 520 ppm enzim papain. Dadih yang terbentuk dipisahkan dari whey, kemudian ditambahkan larutan $\mathrm{NaCl} 4 \%$.

\section{Fortifikasi mikroenkapsulat minyak belut pada keju cottage}

Fortifikasi dilakukan dengan menambahkan $2 \%$, $6 \%$, dan $10 \%$ mikroenkapsulat minyak belut pada keju cottage. Kemudian hasil fortifikasi dianalisis hedonik. Hasil terbaik kemudian dianalisis kandungan asam lemaknya menggunakan GCMS.

\section{Penentuan profil asam lemak menggunakan GCMS}

Minyak hasil ekstraksi mikroenkapsulat hati sapi ditambahkan boron tri flourida (BF3) dengan perbandingan 1:3 kemudian diaduk menggunakan stirrer dan dipanaskan pada suhu $50{ }^{\circ} \mathrm{C}$ selama 1 jam. Selanjutnya diuji menggunakan alat GC-MS.

\section{HASIL DAN PEMBAHASAN}

Hasil minyak yang didapatkan dari proses ekstraksi dan pemurnian 800 gram daging belut sebanyak 29,64 gram atau 3,7\% . Jenis asam lemak yang terkandung dalam minyak belut ditunjukkan pada Tabel 1.

Tabel 1. Komposisi asam lemak minyak belut

\begin{tabular}{|c|c|c|c|}
\hline $\begin{array}{c}\text { No. } \\
\text { Puncak }\end{array}$ & $\begin{array}{l}\text { Waktu } \\
\text { Retensi }\end{array}$ & $\begin{array}{c}\text { Perkiraan nama asam } \\
\text { lemak }\end{array}$ & $\%$ \\
\hline 1 & 16.289 & Metil tetradekanoat & 0,99 \\
\hline 2 & 18.446 & $\begin{array}{l}\text { Cis,5,8,11,14,17- } \\
\text { Eikosapentanoat }\end{array}$ & 1,03 \\
\hline 3 & 18.649 & $\begin{array}{l}\text { Asam Linolenat } \\
\text { metil ester }\end{array}$ & 0,61 \\
\hline 4 & 18.649 & $\begin{array}{c}\text { 9-metil } \\
\text { heksadekanoat }\end{array}$ & 4,87 \\
\hline 5. & 18.902 & $\begin{array}{l}\text { Asam dekanoat,metil } \\
\text { ester }\end{array}$ & 16.03 \\
\hline 6. & 19.716 & $\begin{array}{c}\text { Asam } \\
\text { heksadekanoat, etil } \\
\text { ester }\end{array}$ & 0,83 \\
\hline 7. & 20.847 & $\begin{array}{l}\text { Cis,5,8,11,14,17- } \\
\text { Eikosapentanoat }\end{array}$ & 0,90 \\
\hline 8. & 20.956 & 9,12 -oktadekadienat & 31,92 \\
\hline 9. & 21.001 & 9-oktadekanoat & 27,67 \\
\hline 10. & 21.185 & $\begin{array}{c}9,12,15- \\
\text { oktadekatriena }\end{array}$ & 0,76 \\
\hline 11. & 21.275 & $\begin{array}{c}\text { Asam } \\
\text { oktadekanoat,metil } \\
\text { ester }\end{array}$ & 5.00 \\
\hline 12. & 22.886 & $\begin{array}{l}\text { Cis,5,8,11,14,17- } \\
\text { Eikosapentanoat }\end{array}$ & 6,11 \\
\hline 13. & 24.821 & $\begin{array}{l}4,7,10,13,16,19- \\
\text { Deoksiheksanoat }\end{array}$ & 2,61 \\
\hline 14. & 29.070 & Kolesterol & 0,67 \\
\hline
\end{tabular}


Berdasarkan Tabel.1 diketahui bahwa pada minyak belut terkandung tiga jenis asam lemak omega-3 yaitu ALA, EPA dan DHA. Total asam lemak omega-3 yang terukur oleh instrumen GC-MS sebesar $11,62 \%$. Hasil proses ektraksi dan pemurnian didapat jumlah yang relatif kecil. Hal ini dikarenakan kandungan lemak pada belut dapat dipengaruhi oleh musim dan daerah tempat belut hidup. Pemisahan yang kurang sempurna juga menjadi faktor kecilnya jumlah minyak yang didapat. Setelah diketahui komponen asam lemak yang terkandung dalam minyak belut, minyak belut kemudian diformulasikan dengan bahan penyalut berupa maltodeksrin dan gum arab untuk selanjutnya dibuat mikroenkapsulat

Berdasarkan hasil formulasi mikroenkapsulat, didapatkan data stabilitas mikroenkapsulasi yang ditunjukkan pada Tabel 2.

Tabel 2. Optimasi komposisi bahan penyalut mikroenkapsulat minyak belut

\begin{tabular}{|c|c|c|c|c|c|}
\hline \multirow[t]{2}{*}{ Kode } & \multirow{2}{*}{$\begin{array}{c}\text { Jumlah } \\
\text { minyak } \\
\text { yang } \\
\text { diemuls } \\
\text { ikan } \\
(\mathrm{mL})\end{array}$} & \multirow{2}{*}{$\begin{array}{l}\text { Jumlah } \\
\text { pelarut } \\
\text { air yang } \\
\text { digunak } \\
\text { an }(\mathrm{mL})\end{array}$} & \multicolumn{2}{|c|}{$\begin{array}{l}\text { Perbandingan } \\
\text { komposisi bahan } \\
\text { penyalut }\end{array}$} & \multirow{2}{*}{$\begin{array}{c}\text { Stabi } \\
\text { litas } \\
\text { emul } \\
\text { si } \\
(\%)\end{array}$} \\
\hline & & & $\begin{array}{l}\text { Maltod } \\
\text { ekstrin } \\
\text { (bagian }\end{array}$ & $\begin{array}{c}\text { Gom } \\
\text { arab } \\
\text { (bagi } \\
\text { an) }\end{array}$ & \\
\hline K1 & - & 100 & 5 & 1 & 100 \\
\hline K2 & - & 100 & 4 & 2 & 50 \\
\hline K3 & - & 100 & 3 & 3 & 30 \\
\hline K4 & - & 100 & 2 & 4 & 40 \\
\hline
\end{tabular}

Data Tabel 2 menunjukkan komposisi yang memberikan efisiensi terbaik yaitu K1 dengan perbandingan 5:1, dengan stabilitas emulsi $100 \%$. Stabilitas mikroenkapsulasi dihitung berdasarkan jarak keterpisahan minyak dengan bahan penyalutnya. Formula dengan kode K1 dan K2 memiliki tekstur yang kering, sedangkan K3 dan K4 teksturnya lengket dan basah. Hal ini dikarenakan semakin banyaknya penambahan gom arab akan menyebabkan viskositas fase air dari emulsi meningkat. Meningkatnya viskositas ini mengakibatkan lama pengeringannya berjalan lambat. Sehingga formula K1 dipilih untuk dianalisis pada tahap karakterisasi.

Berdasarkan hasil karakterisasi diketahui rendemen yang dihasilkan $74 \%$ (b/b); efisiensi 64,29\%; kadar air 1,03. Analisis dengan menggunakan SEM ditunjukkan pada Gambar 1.

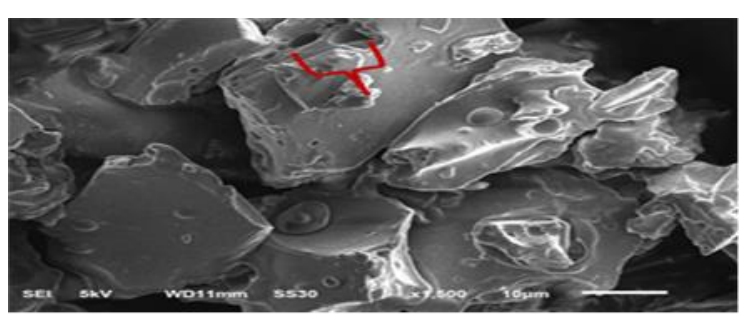

Gambar 1. Analisis SEM mikrokenkapsulat minyak belut
Berdasarkan Gambar 1 diketahui ukuran mikroenkapsulat sebesar $\pm 10-50 \mu \mathrm{m}$; struktur permukaan tidak teratur; dan mikroenkapsulat memiliki pori dengan diameter $\pm 5 \mu \mathrm{m}$. Dari hasil analisis terlihat struktur permukaan mikroenkapsulat yang kasar dan tidak teratur, diduga diakibatkan dari laju pendinginan yang tidak kontinu. Permukaan mikroenkapsulat berongga yang diakibatkan adanya busa saat dalam keadaan emulsi cair. Berdasarkan dari gambar didapat ukuran rongga yang dihasilkan \pm $5 \mu \mathrm{m}$. Jika dibandingkan dengan hasil penelitian Kolanowski (2006) menunjukkan ukuran rongga yang lebih besar yaitu $\pm 10 \mu \mathrm{m}$, namun hal tersebut tidak terlalu berpengaruh terhadap tingkat oksidasi minyak tak jenuh didalamnya.

Analisis bilangan iod dan bilangan peroksida ditunjukkan pada Gambar 2.

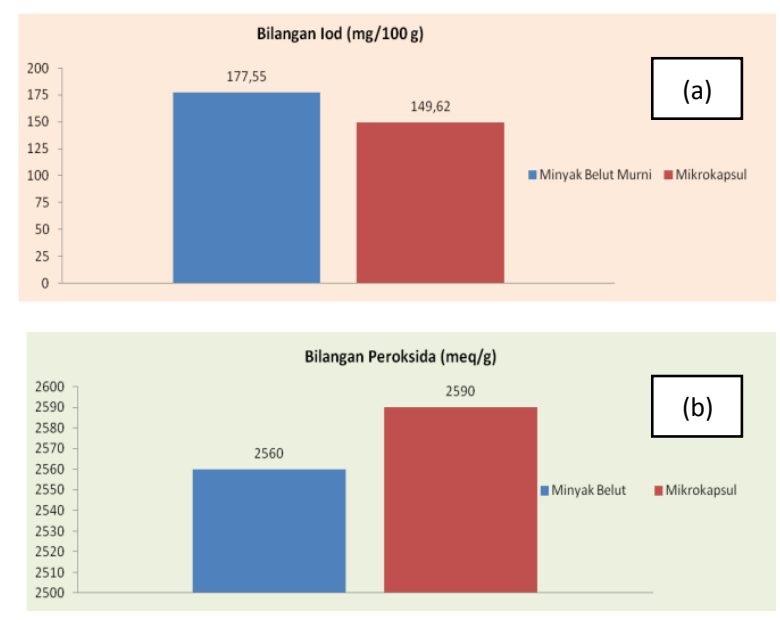

Gambar 2. (a) Hasil analisis bilangan iod; (b) hasil analisis bilangan peroksida

Dari Gambar 2 dapat diketahui bahwa terjadi penurunan kualitas minyak belut sebelum dan setelah proses mikroenkapsulasi. Adanya penurunan bilangan iod dan kenaikan bilangan peroksida pada mikroenkapsulat dapat disebabkan oleh adanya proses oksidasi asam lemak. Reaksi oksidasi asam lemak pada proses freeze drying sangat mungkin terjadi karena asam lemak tak jenuh pada sampel mengalami kontak dengan sejumlah oksigen. Selain itu, reaksi oksidasi asam lemak dapat dipengaruhi oleh enzim peroksidase, dan cahaya (radiasi). Oksidasi minyak umumnya akan berlangsung melalui mekanisme reaksi radikal bebas.

Pada proses pembuatan keju, susu skim sebagai bahan dasar di pasteurisasi pada suhu $63{ }^{\circ} \mathrm{C}$ selama 10 menit. Susu skim hasil pasteurisasi kemudian didinginkan hingga suhu $40{ }^{\circ} \mathrm{C}$ dan diinokulasikan dengan bakteri starter sebesar $4 \%$ v/v. Penambahan enzim bertujuan untuk mengkoagulasi misel kasein dalam susu. Setelah pH mencapai 4,6 ( titik isolistrik kasein), terbentuk koagulan berwarna putih yang disebut dadih dan merupakan hasil koagulasi kasein. Fasa bagian bawah berbentuk cairan berwarna kuning 
yang disebut dengan whey, dapat dilihat pada Gambar 3.

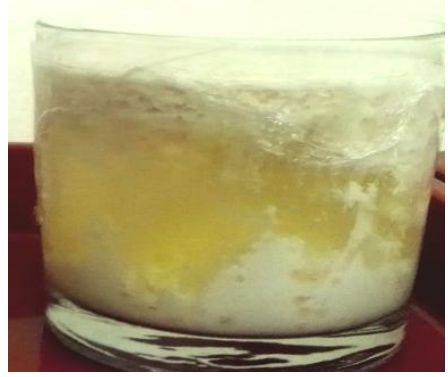

Gambar. 3 Proses Pembentukan dadih (bagian atas) dan whey (bagian bawah)

Pada tahap pemisahan whey dan dadih dilakukan pemanasan dan pembilasan, kemudian pada dadih ditambahkan 4\% $\mathrm{NaCl}$. Pemanasan dadih dilakukan pada suhu $90{ }^{\circ} \mathrm{C}$ untuk menghentikan proses fermentasi. Sedangkan pembilasan bertujuan untuk menghilangkan sisa asam pada dadih. Sehingga dihasilkan dadih dengan rasa yang asin.

Produk mikroenkapsulat yang telah diperoleh, difortifikasikan pada keju cottage dengan variasi penambahan yang berbeda, kemudian diuji hedonik untuk mendapatkan keju dengan tingkat kesukaan yang paling baik. Uji hedonik terhadap keju cottage dilakukan oleh 30 orang panelis tidak terlatih. Pengujian meliputi warna, aroma, rasa, dan tekstur. Skala penilaian yang diberikan pada rentang 1-3. Skala 1 menunjukan tidak suka, 2 menunjukan cukup suka, 3 menunjukkan suka. Berdasarkan hasil uji hedonik diperoleh data pada Tabel.3.

Tabel 3. Hasil pengujian hedonik terhadap warna, aroma, tekstur dan rasa keju cottage

\begin{tabular}{ccccc}
\hline Penambahan & \multicolumn{4}{c}{ Tingkat kesukaan } \\
mikroenkapsulat & Aroma & Warna & Tekstur & Rasa \\
\hline Blanko & 2,5 & 2,2 & 1,9 & 2,2 \\
$2 \%$ & 1,67 & 2,2 & 2,0 & 1,7 \\
$6 \%$ & 1,53 & 2,27 & 2,2 & 1,6 \\
$10 \%$ & 1,37 & 2,3 & 2,5 & 1,5 \\
\hline
\end{tabular}

Berdasarkan Tabel.3 dapat diketahui bahwa skala hedonik aroma menunjukkan skala numerik 1,37-2,5, yang berarti tingkat kesukaan berada antara tidak suka (1) dan suka (3). Berdasarkan analisis statistik Kurskal Wallis menunjukkan bahwa antar sampel memiliki perbedaan secara nyata Asym.sig $0,000<0,05$ dengan sampel yang paling disukai adalah blanko. Panelis memiliki tingkat kesukaan terhadap aroma yang berbeda-beda. Aroma pada setiap sampel dipengaruhi oleh penambahan mikroenkapsulat.

Skala hedonik warna menunjukkan skala numerik 2,2-2,3, yang berarti tingkat kesukaan berada angka 2 cukup suka. Berdasarkan analisis statistik Kurskal Wallis menunjukkan Asym. Sig
0,936 tidak lebih kecil dari 0,05 berarti antar sampel tidak memiliki perbedaan secara nyata, karena warna keju (putih kekuningan) dan mikroenkapsulat minyak belut putih, keduanya tidak jauh berbeda. Panelis memiliki tingkat kesukaan yang sama terhadap setiap sampel, dan sampel yang paling disukai adalah penambahan mikroenkapsulat minyak belut $10 \%$

Skala hedonik tekstur menunjukkan skala numerik 1,9-2,5 yang berarti tingkat kesukaan berada antara cukup suka (2) dan suka (3). Berdasarkan analisis statistik Kurskal Wallis menunjukkan bahwa antar sampel memiliki perbedaan secara nyata Asym.sig 0,041 < 0,05 dengan sampel yang paling disukai adalah blanko. Dengan semakin banyaknya penambahan mikroenkapsulat minyak belut, keju cottage semakin kental. Maka pada uji hedonik tekstur ini keju cottage yang paling disukai adalah dengan penambahan mikroenkapsulat $10 \%$.

Skala hedonik rasa menunjukkan skala numerik 1,5-2,2 yang berarti tingkat kesukaan berada antara tidak suka (1) dan cukup suka (2). Berdasarkan analisis statistik Kurskal Wallis menunjukkan bahwa antar sampel memiliki perbedaan secara nyata Asym.sig $<0,05$ dengan sampel yang paling disukai adalah blanko. Rasa dipengaruhi oleh banyaknya mikroenkapsulat yang ditambahkan, karena semakin banyak mikroenkapsulat ditambahkan maka keju semakin amis.

Berdasarkan temuan tersebut menunjukkan panelis memiliki tingkat kesukaan yang berbeda-beda dengan produk yang paling disukai yaitu keju dengan penambahan $10 \%$ mikroenkapsulat minyak belut. Sehingga produk keju cottage dengan penambahan mikroenkapsulat $10 \%$ dianalisis kandungan asam lemak dengan GC-MS.Untuk mengetahui komposisi relatif asam lemak jenuh (Saturated fatty acid/SFA) dan asam lemak tak jenuh tunggal (Monounsaturated fatty acid/MUFA) serta asam lemak tak jenuh ganda (Polyunsaturated fatty acid/PUFA) pada sampel, asam lemak pada sampel keju terlebih dahulu diderivatisasi dengan metode transesterifikasi. Derivatisasi dilakukan untuk menurunkan titik didih dari asam lemak agar lebih mudah diuapkan dan dipisahkan sehingga menghasilkan pemisahan dengan resolusi yang baik. Pemisahan derivat asam lemak (fatty acid methyl ester) dilakukan dalam kondisi suhu kolom $60{ }^{\circ} \mathrm{C}$ dan dinaikkan sampai 290 ${ }^{\circ} \mathrm{C}$ dengan laju alir ,61 mL/menit. Adapun hasil analisis komposisi asam lemak untuk masing-masing sampel lemak terdapat pada Tabel 4.

Dari hasil analisis GCMS pada Tabel 4, dapat dilihat puncak paling tinggi ialah puncak nomor 6 yang menunjukkan senyawa asam askorbat 2,6diheksadekanoat. Adanya senyawa ini dimungkinkan karena masih terdapatnya bakteri starter keju. Dari hasil metabolisme bakteri starter dapat dihasilkan enzim lipase. Enzim lipase ini akan mengkatalisis sintesis enzimatik derivat ascorbil menggunakan asam lemak jenuh dan tak jenuh. Sehingga dalam 
penelitian selanjutnya perlu diketahui cara yang lebih sesuai untuk mematikan bakteri dalam produksi keju cottage.

Berdasarkan data Tabel 1 tentang komposisi asam lemak minyak belut dan Tabel 4 komposisi asam lemak keju cottage terfortifikasi menunjukan hasil analisis minyak belut, sehingga berdasarkan kedua tabel tersebut, kandungan masing-masing omega-3 pada sampel dapat di rangkum seperti pada Tabel 5.

Tabel 4. Komposisi asam lemak keju cottage terfortifikasi

\begin{tabular}{|c|c|c|c|}
\hline $\begin{array}{c}\text { No. } \\
\text { Puncak }\end{array}$ & $\begin{array}{l}\text { Waktu } \\
\text { retensi }\end{array}$ & $\begin{array}{c}\text { Perkiraan nama asam } \\
\text { lemak }\end{array}$ & $\%$ area \\
\hline 1 & 1,336 & Methane oxybis & 0,91 \\
\hline 2. & 1,458 & $\begin{array}{c}\text { Acetic acid, methyl } \\
\text { ester }\end{array}$ & 0,72 \\
\hline 3. & 2,076 & $\begin{array}{c}\text { Propanoic acid,2- } \\
\text { hydroxy,methyl, methyl } \\
\text { ester }\end{array}$ & 0,46 \\
\hline 4. & 2,787 & 2-Furancarboxaldehyde & 0,55 \\
\hline 5. & 18,835 & $\begin{array}{l}\text { Pentadecanoic 14- } \\
\text { methyl, methyl ester }\end{array}$ & 1,31 \\
\hline 6. & 19,377 & $\begin{array}{l}\text { Ascorbic acid 2,6 } \\
\text { dihexadecanoate }\end{array}$ & 66,18 \\
\hline 7. & 19,665 & $\begin{array}{l}\text { Hexadecanoic acid, } \\
\text { ethyl ester }\end{array}$ & 1,17 \\
\hline 8. & 20,934 & $\begin{array}{c}\text { 9-0ctadecanoic acid } \\
\text { 1,2,3 propanethyl ester }\end{array}$ & 1,04 \\
\hline 9. & 21,530 & & \\
\hline 10. & 21,615 & 1-heptadecanol & 5,16 \\
\hline 11. & 21,680 & Ethyl oleate & 4,53 \\
\hline 12. & 21,750 & Ethyl oleate & 0,87 \\
\hline 13. & 21,957 & $\begin{array}{l}\text { Hexadecanoic acid, } \\
\text { ethyl ester }\end{array}$ & 0,19 \\
\hline 14. & 23,470 & $\begin{array}{c}4,7,10,13,16,19 \\
\text { decolhexanoide acid }\end{array}$ & 3,96 \\
\hline 15 . & 25,342 & $\begin{array}{c}4,7,10,13,16,19 \\
\text { decolhexanoide acid }\end{array}$ & 2,46 \\
\hline 16. & 25,494 & $\begin{array}{c}\text { Docosapentanoate- } \\
\text { propyl } 4,7,10,13,16,19 \\
\text { decolhexanoide }\end{array}$ & 0,40 \\
\hline
\end{tabular}

Tabel 5. Rekapitulasi hasil analisis asam lemak omega-3 pada sampel

\begin{tabular}{cccc}
\hline Sampel & $\begin{array}{c}\text { Jenis asam } \\
\text { lemak } \\
\text { omega-3 }\end{array}$ & Jumlah \% & Total \% \\
\hline Minyak Belut & ALA & 0,61 & 11,62 \\
& EPA & 8,4 & \\
Keju cottage & DHA & 2,42 & \\
terfortifikasi & & 6,42 & 6,42 \\
\hline
\end{tabular}

Dari data pada Tabel 5, diketahui bahwa asam lemak omega-3 yang terkandung pada sampel keju hanya satu jenis yaitu DHA (Asam Dokosaheksanoat) sedangkan ALA dan EPA tidak ditemukan. Hal tersebut dapat disebabkan oleh adanya interkonversi ALA (Asam Linoleat) dan EPA (Asam Eikosapentanoat) menjadi DHA (Morris, 2007). Interkonversi dapat terjadi karena adanya enzim yang dihasilkan oleh bakteri dan asetil-SCoA berlebih yang merupakan produk katabolisme asam lemak.

\section{KESIMPULAN}

Berdasarkan hasil dan pembahasan terhadap fortifikasi keju cottage menggunakan mikroenkapsulat minyak belut beromega-3, dapat diambil kesimpulan sebagai berikut :

- Teknik pembuatan mikroenkapsulat minyak belut yang digunakan yaitu dengan teknik freeze drying menggunakan bahan penyalut maltodekstrin dan gum arab dengan rasio 5:1, yang merupakan formulasi terbaik. Formulasi ini menghasilkan stabilitas emulsi sebesar $100 \%$. Rendemen mikroenkapsulat minyak belut yang dihasilkan dengan teknik ini sebesar $74 \%$.

- Karakteristik mikroenkapsulat minyak belut yang dihasilkan memiliki efisiensi 64,29\%, ukuran mikroenkapsulat sebesar $10-50 \mu \mathrm{m}$, kadar air 1,03\%. Berdasarkan uji bilangan iod dan uji bilangan peroksida, terjadi penurunan kualitas dari minyak belut hasil mikroenkapsulasi, yang menunjukkan berkurangnya ikatan tak jenuh.

- Produk keju cottage yang difortifikasi dengan $10 \%$ mikroenkapsulat minyak belut memiliki kandungan omega-3 sebesar $6,42 \%$. Berdasarkan uji hedonik yang dilakukan, didapat bahwa keju cottage terfortifikasi $10 \%$ memiliki tingkat kesukaan warna dan tekstur yang tertinggi.

\section{DAFTAR PUSTAKA}

Gupta, C., Chawla, P., Arora, S., Tomar, S.K., \& Singh, A.K., (2014), Iron microencapsulation with blend of gum arabic, maltodextrin and modified starch using modified solvent evaporation methodmilk fortification., Food Hydrocolloids, 30, 1-7.

De souza, J.R.R., Feitosa, J.P.A, Ricardo, N.M.P.S., Trevisan, M.T.S., De Paula, H.C.B, \& Ulrich, C.M., (2013). Spray drying encapsulation of mangiferin using natural polymer. Food Hydrocolloids, 33(1), 10-18.

Estrada, J.D., Boeneke, J., Bechtel, P., \& Sathivel, S. (2011). Developing a strawberry yogurt fortified with marine fish oil. Journal of Dairy Science, 94, 5760-5769.

Kolanowski, W., Ziolkowski, M., Weibrod, J., Kunz, B., \& Lauvenberg, G. (2006). Microencapsulation of fish oil by spray drying Impact on oxidative stability . Part 1. European Food Research and. Technology. 222, 336-342.

Kusdiantini, A. (2010). Studi pengaruh Pengontakan Bentonit dalam Proses Ekstraksi Terhadap Kualitas dan Kuantitas Minyak Belut. 
Skripsi. Jurusan Kimia, Universitas Pendidikan Indonesia

Mediana, A, R., Gimenez, A, G, Camacho, F.G, Perz, J.A.S., Grima, E.M, \& Gomez, A.C. (1995). Concentration and Purification of Searidonic, Eicosa Pentaoic Acid, And Docosahexanoic Acid Cod Liver Oil and The Marine Microalga. Journal of American Oil Chemical Society, 72 (5), 575-581.

Morris, D. H. (2007). Metabolism of alpha Linoleic Acid. Flax Council Canada:Canada.

Razak, Z.K.A., Basri, M., Dzulkefly, K., Razak, C.N.A., \& Salleh, A.B. (2000). Extracton and caracterization of Fish Oil Monoptrus albus. Malaysian Journal of Analiytical Science, 7 (1), 217-220.

Sathivel, S. \& Kramer, D.E., (2010), Microencapsulation, nanoencapsulation, edible film, and coatings applications in seafood processing. In C. Alasalvar , K. Miyasitha, F. Shahidi and U. Wanasundara (Eds.) Seafood Quality Safety, and Health effect, Blackwell Publishing Ltd., Oxford, UK. Pages 414-422 